European standardization of quality specifications for roadway bridges

Organizers: J.A.S. de Carvalho, C. Matos \& J. Casas 


\title{
COST Action TU1406 Quality Specifications for Roadway Bridges (BridgeSpec)
}

\author{
J. Campos e Matos \\ Civil Engineering Department, University of Minho, Guimarães, Portugal
}

J.R. Casas

Technical University of Catalonia BarcelonaTech, Barcelona, Spain

\author{
S. Fernandes \\ Anser, Santo Tirso, Portugal
}

\begin{abstract}
Roadway bridges, being one of the most critical road infrastructures components, require regular maintenance actions. Therefore, it becomes important to define strategies to maximize societal benefits, derived from the investment made in these assets. Consequently, this investment should be planned, effectively managed and technically supported by appropriate management systems, supported in quality control plans. For this purpose, authorities need to produce an asset management plan which should, not only define the goals to be achieved by exploiting the roadway bridge network, but also identify the investment needs and priorities based on a life cycle cost criteria. Additionally, a proper condition assessment of these assets must be conducted to support the decision-making process regarding their preservation. A COST Action recently started in Europe with the aim of standardizing the establishment of quality control plans for roadway bridges. This paper describes this Action and, particularly, its most recent developments.
\end{abstract}

\section{INTRODUCTION}

In engineering, quality control (QC) is related to systems development in order to ensure that products or services meet the expectations and needs of users. Concerning road infrastructures, it can be said that asset management and QC are two sides of the same coin. Though they belong to the domain of public service, their management mechanism can be conducted by the state or under a private public partnership. However, in both cases, there is an increasing need of developing strategies to ensure the quality of the entire system.

Road asset management is a task of great responsibility, since it involves vital assets to the community. An efficient transportation network is essential for the modern society from the economic, societal and environmental point of view. Today, it is a challenge for operators to manage road infrastructures under their responsibility in an efficient way, meeting the present and future needs of the community they serve.

Some of the main outcomes from the correct implementation of strategies for roadway bridges management are: (i) an improved user satisfaction, by improving the quality of provided service; (ii) an improved sustainable performance; (iii) a guarantee of a pre-specified safety level; (iv) an optimized return of investment; (v) a long-term planning and re- liable performance; and (vi) an improved risk management.

For this purpose, the authorities need to produce an asset management plan, which should not only define the goals to be achieved by exploiting the roadway bridge network, but that should also identify the investment needs and priorities based on a life cycle cost criteria. In addition, a proper condition assessment of these assets must be conducted to support the decision-making process regarding their preservation.

In Europe, as all over the world, the need to manage roadway bridges in an efficient way led to the development of different management systems (Arangio \& Beck 2012, Biondini \& Frangopol, 2008, Kumar \& Imam 2013, Landolfo 2011, Linneberg et al. 2011, 2012, Masovic \& Hajdin 2014, Orcesi \& Cremona 2010). Hence, nowadays, many countries have their own system. Although they present a similar architectural framework, several differences can be appointed, for example, with regard to the condition assessment procedure (Adelaide et al. 2011, Bjegovic et al. 2013, Coronelli et al. 2013, Hanjari et al. 2013, Ivankovic et al. 2013, Jensen et al. 2009, Kuosa et al. 2014, Matos et al. 2012, Meda et al. 2014, Novák et al. 2012, 2013, Oslakovic et al. 2010, Santos et al. 2013, Strauss et al. 2013). These differences constitute a divergent mechanism that may conduct to different decisions on maintenance actions. 
Within the roadway bridge management process, the identification of maintenance needs is more effective when developed in a uniform and repeatable manner. This process can be accomplished by the evaluation of performance indicators, improving the planning of maintenance strategies. Therefore, a discussion at a European networking level, seeking to achieve a standardized approach in this subject, will bring significant benefits. Accordingly, a COST Action recently started in Europe with the aim of standardizing the establishment of QC plans for roadway bridges (European Cooperation in the field of Scientific and Technical Research - COST 2014).

In this context, a first step would be the establishment of specific recommendations for the assessment of roadway bridges, namely, used methods for the quantification of performance indicators. A set of reference time periods for these assessment actions should be also presented. A second step would be the definition of standardized performance goals. Finally, a guideline for the establishment of QC plans in roadway bridges would be developed. In these plans, it is emphasized the importance of advanced deterioration prediction models. Moreover, the concept of sustainable roadway bridge management, involving the evaluation of environmental, economic and social performance indicators during the whole life cycle, is also highlighted.

By developing new approaches to quantify and assess bridge performance, as well as quality specifications to assure an expected performance level, bridge management strategies will be significantly improved, enhancing asset management of ageing structures in Europe.

\section{CURRENT STATE OF KNOWLEDGE}

Within last years, significant research has been developed worldwide regarding the condition assessment of roadway bridges, namely through the use of non-destructive tests, monitoring systems and visual inspection techniques (Bjegovic et al. 2013, Coronelli et al. 2013, Ivankovic et al. 2013, Kuosa et al. 2014, Matos et al. 2012, Meda et al. 2014, Oslakovic et al. 2010, Strauss et al. 2013). Obtained values, which will provide information regarding the assessed bridge state condition, were then compared with previously established goals. As a result, there are nowadays several ways of evaluating a bridge condition.

More recently, the concept of performance indicators was introduced, simplifying the communication between consultants, operators and owners. However, large deviations are still verified on how these indicators are obtained and, therefore, specific actions should be undertaken in order to standardize this procedure.
It is verified that QC plans should always address the assessed performance indicators and prespecified goals (Arangio \& Beck 2012, Linneberg et al. 2011, 2012, Masovic \& Hajdin 2014, Orcesi \& Cremona 2010). However, these latter values are even more difficult to obtain as they are highly subjective. As a result, a dispersion of QC plans is verified. Once roadway concession contracts are based on such plans, this may become an enormous problem for the future of our society.

It is known that in the past a similar problem was addressed with roadway pavements. Although this was verified worldwide, in Europe it was solved through COST Action 354, performance indicators for pavements (European Cooperation in the field of Scientific and Technical Research - COST 2003). In a similar way, during this Action, a network of experts in the field of roadway bridges will establish specific recommendations for assessing performance indicators as well as for the definition of corresponding goals. This activity will be supported in a data basis, gathered from different COST countries. The objective is to develop a guideline for the establishment of QC plans in roadway bridges.

Moreover, it will be also analyzed the possibility of incorporating new indicators related to sustainable performance of roadway bridges. Some of these indicators were evaluated with success within the COST Action $\mathrm{C} 25$, sustainability of constructions: integrated approach to life-time structural engineering (European Cooperation in the field of Scientific and Technical Research - COST 2005). The final purpose is to establish detailed recommendations for assessing them as well as for the definition of specific goals, in a similar way as for the other indicators, and then integrating it in the developed guideline.

\section{HISTORY}

The Action proposal arose due to the existing concern from owners, operators, consultants and researchers regarding the existence of multiple methodologies to assess and classify roadway bridges state condition. Within an R\&D project developed in Portugal (SustIMS - Sustainable Infrastructure Management System; https://www.youtube.com/watch? v=Ls1W5oxVD8w ), which aims to develop a cross-asset management system for highways, one of the partners encouraged the idea of standardizing the existing practice.

In a first stage, a national analysis to assess the potential of the idea was performed, having been addressed two entities for the purpose: the Portuguese Association of Highway Operators, that confirmed the same concern, and the Portuguese Roadway Agency, who established the assessment criteria for roadway bridges condition in Portugal. 
Having obtained a positive feedback, some contacts were performed at European level and a first team, with experts from different European countries, research fields and stakeholders, was established to work on this issue. Within this team, it was considered that the COST Association platform would be the most suitable framework to support this project.

From the approval of the proposal resulted the Action's Memorandum of Understanding which is available in the official website of COST Association

http://www.cost.eu/COST Actions/tud/TU1406 and also on the Action official website (www.tu1406.eu).

The action was officially started in April 16, 2015 and will last for four years, ending on April 15, 2019. Currently are involved 174 experts from 44 different countries, see Figure 1, distributed between the Management Committee and the various working groups. After the initial kick-off Meeting, the Action will be carried out according to the timetable provided in Figure 2. An open call to Join the Action is permanently open at the Action website.

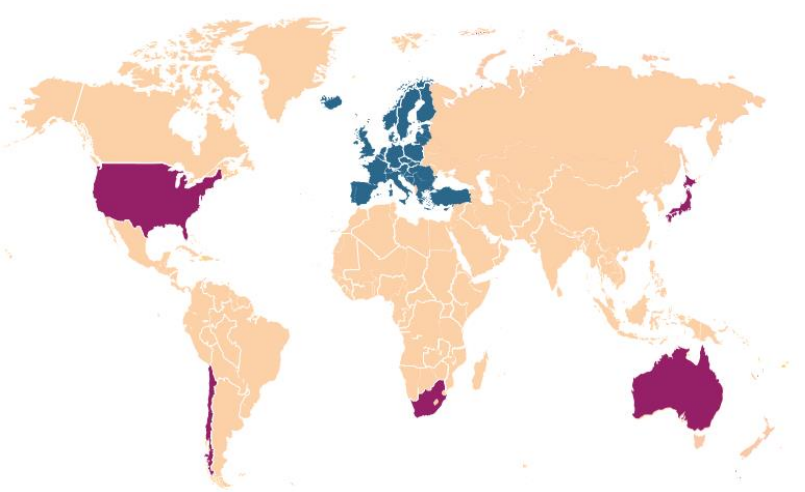

Figure 1. COST Action TU1406 countries.

\section{OBJECTIVES}

The main ambition of the COST Action TU 1406, Quality Control Specifications for Roadway Bridges - Standardization at an European Level, is to develop a guideline for the establishment of QC plans in roadway bridges, by integrating the most recent knowledge on performance assessment procedures with the adoption of specific goals (European Cooperation in the field of Scientific and Technical Research - COST 2014)

This guideline will focus on bridge maintenance and life-cycle performance at two levels: (i) performance indicators, and (ii) performance goals. By developing new approaches to quantify and assess the bridge performance, as well as quality specifications to assure an expected performance level, bridge management strategies will be significantly im- proved, enhancing asset management of ageing structures in Europe.

In order to reach this main general aim, the following more specific objectives/deliverables have been considered: (i) to systematize knowledge on QC plans for bridges, which will help to achieve a state-of-art report that includes performance indicators and respective goals; (ii) to collect and contribute to up-to-date knowledge on performance indicators, including not only technical indicators but also environmental, economic and social ones; (iii) to establish a wide set of quality specifications through the definition of performance goals, aiming to assure an expected performance level; (iv) to develop detailed examples for practicing engineers on the assessment of performance indicators as well as in the establishment of performance goals, to be integrated in the developed guideline; (v) to create a data basis from COST countries with performance indicator values and respective goals, that can be useful for future purposes; (vi) to develop a webpage with information about the Action and its participants, as well as, video-streaming from presentations at training schools, workshops and conferences, e-lectures, written material (e.g. technical reports), etc.; (vii) to support the development of technical/scientific committees; and (viii) to disseminate activities, such as Short-Term Scientific Missions (STSM), training schools and other teaching activities (e.g. e-lectures), for practicing engineers and researchers, regular workshops, a conference and special sessions at international conferences.

\section{TARGET GROUPS/END USERS}

The target groups and end users who will exploit the outcome of this Action are: (i) public/private owners, as their assets will be maintained in an upscale level; (ii) operators, as standardized procedures for reducing maintenance costs, guaranteeing the same quality-level, will be introduced; (iii) design and consultant engineers, as the assessment of roadway bridges performance will be established in a uniform way, according to the developed guideline; (iv) equipment and software companies, as a new perspective will be given, regarding the most suitable equipment and software for the assessment of roadway bridges; (iv) academics and researchers engineers, as they will take an advantage of their involvement in the guideline preparation; (v) students, as they will benefit from COST tools (e.g. training schools) and from the contact with different stakeholders, involved in this Action; (vi) relevant European, international and national associations, with which the main outcomes of this Action will be shared; and (vii) standardization bodies and code writers, which will benefit from the developed guideline. 


\section{SCIENTIFIC PROGRAMME}

The scientific focus of the Action is centered in the production of a guideline for the establishment of QC plans for roadway bridges across Europe. In this context, this Action deals with recent developments on bridge safety, maintenance and management, according to a life-cycle outlook, aiming to define a standardized procedure for performance assessment as well as for the establishment of performance goals in order to accomplish a pre-specified service level. Moreover, it is intended to demonstrate the applicability of the developed guideline, and other recommendations, with case studies.

The scientific work plan of this Action ensures the working progress in support of the objectives established. It is organized, based on the division of tasks (and subtasks) allocated for each WG, and according to a timetable, Figure 2. At this moment, only WG1, WG3 and WG6 started. A description of all WGs, including the corresponding milestones, is further present, being WG6 dedicated to dissemination activities.

\begin{tabular}{|c|c|c|c|c|c|c|c|c|c|c|c|c|c|c|c|c|}
\hline Activity/Months & 3 & 6 & 9 & 12 & 15 & 18 & 21 & 24 & 27 & 30 & 33 & 36 & 39 & 42 & 45 & 48 \\
\hline Meeting & $\mathrm{x}$ & & & $\mathrm{x}$ & & $x$ & & $x$ & & $x$ & & $\mathrm{x}$ & & $\mathrm{x}$ & & $x$ \\
\hline Workshop & & & & $x$ & & & & $x$ & & & & $x$ & & & & \\
\hline Conference & & & & & & & & & & & & & & & & $x$ \\
\hline Training school & & & & & & & & $x$ & & & & $\mathrm{x}$ & & & & $\mathrm{x}$ \\
\hline STSM & $x$ & $x$ & $x$ & $x$ & $x$ & $x$ & $\mathrm{x}$ & $x$ & $x$ & $x$ & $x$ & $x$ & $x$ & $x$ & $x$ & $x$ \\
\hline Website & $x$ & & & $x$ & & $\mathrm{x}$ & & $x$ & & $x$ & & $\mathrm{x}$ & & $\mathrm{x}$ & & $x$ \\
\hline Milestone & & & & M1 & & & & M2 & & M3 & & & & M4 & & M5 \\
\hline
\end{tabular}

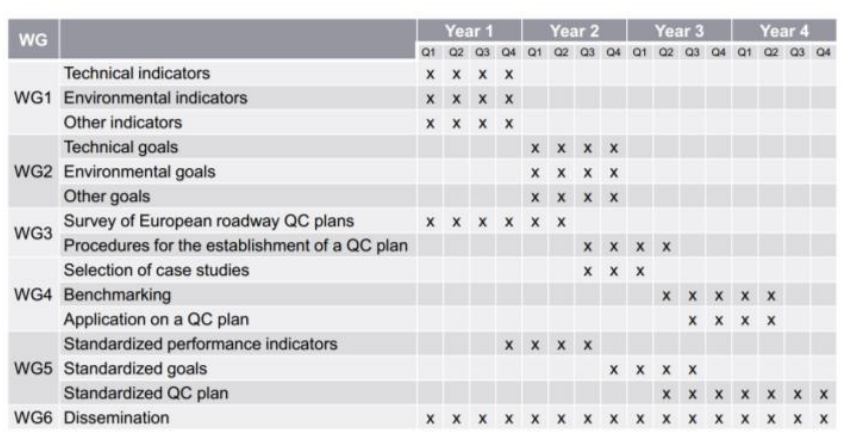

Figure 2. Timetable.

\subsection{WG1: Performance indicators}

It is known that management systems are supported in QC plans which in turn are supported by performance indicators. Therefore, it is highly important to analyze such indicators in terms of used assessment frameworks (e.g. what kind of equipment and software is being used), and in terms of the quantification procedure itself. In this particular work package, the objectives will be the definition of:

(a) Technical indicators: the goal in the first step is to explore bridge performance indicators, in the course of international research cooperation, which capture the mechanical and technical properties and its degradation behavior. Moreover, environmental condition, natural aging, and the quality of the mate- rial regarding to determined indicators will be investigated and evaluated in their meaningfulness. These considerations, however, also include service life design methods, aimed at estimating the period of time during which a structure or any component is able to achieve the performance requirements defined at the design stage with an adequate degree of reliability. On the basis of the quality of input information (mainly concerning with the available degradation models), as sketched in the above description, it is possible to distinguish among deterministic methods, usually based on building science principles, expert judgment and past experience, which provide a simple estimation of the service life, and probabilistic methods;

(b) Sustainable indicators: in addition to technical performance indicators, which characterize the ultimate capacity as well as serviceability conditions, environmental based sustainability indicators, will also be formulated. These variables characterize the environmental impact of a structure in the course of its total life cycle, expressed in terms of total energy consumption, carbon footprint ( $\mathrm{CO} 2$ emission), raw materials balance, etc. These indicators can be separated into direct and indirect indicators, where the former are related to the construction/maintenance itself and the latter are caused e.g. as a consequence of limited functionality;

(c) Other indicators: other sustainable indicators, economic and social based, may be used to evaluate a bridge performance. These indicators, based on the technical performance of a structure, capture additional aspects that may influence the decision process and typically represent the discounted (accumulated) direct or indirect costs associated with construction and maintenance. Summed up over the full life-time, they represent part of or the full lifecycle costs. They can, in the context of multiobjective optimization, be understood as a weighting scheme to arrive to a single objective function to be minimized.

The milestone for this task (M1) is the publication of a report on these performance indicators until the end of year 1. Such report will address a general description, how they are assessed (e.g. visual inspection, non-destructive tests and monitoring systems), with what frequency, what values are generally obtained and, finally, some general recommendations. This outcome will be one of the main inputs of WG5, being also used by WG3

\subsection{WG2: Performance goals}

The main objective of this workgroup is to define a set of goals for the indicators previously identified in WG1. These goals will vary according to technical, environmental, economic and social factors. Specific recommendations will be given in order to ensure that the definition of such goals should be the most 
generalized as possible. In particular, it will be established:

(a) Technical goals: it will be analyzed what goals are actually used for technical performance indicators in roadway bridges and its components (e.g. bearing, joint, etc.). It will be also evaluated which are being defined in the course of international research cooperation. There will be an open discussion within the experts' network in this field, in order to determine the most important factors for the definition of such goals as well as the most suitable threshold values. It will be established goals, both for deterministic and probabilistic methods, for timevarying indicators and for different assessment procedures (e.g. visual inspection, non-destructive tests and monitoring systems);

(b) Sustainable goals: specific goals will be defined for sustainable indicators, environmental based. This task is much more difficult to perform than for technical indicators, as the historical data basis is much smaller. Nevertheless, an open discussion will be established within a network of experts in this field, in order to identify the most important factors for the definition of these goals as well as the most appropriate threshold values;

(c) Other goals: the definition of goals for other sustainable indicators, economic and social based, is extremely difficult as it largely depends on the established agreement between the owner and the roadway operator (concession model). Nevertheless, it will be important for the future of Europe to define such goals, or at least to provide some recommendations, so that standardized procedures can be implemented. In order to achieve this objective, an open discussion will be developed among a network of experts.

The milestone for this task (M2) is the publication of a report on performance goals until the end of year 2. Such report will address a description of the most important technical, environmental, economic and social factors, how to compute each goal, with what frequency, what values are generally obtained as well as some general recommendations. This outcome will be one of the main inputs of WG5, being also used by WG3.

\subsection{WG3: Establishment of a QC plan}

The desired service quality of the whole bridge can be affected by a single dysfunctional component or by the combination of several dysfunctional components. The decrease in bridge service quality clearly depends on the degree of components' dysfunctionality. This dependency can be modelled, among others, by Bayesian nets, which provide the time variation of each bridge component performance.

However, in order to assure a desired service quality with minimum interruptions, bridge owners launch preventative actions when the risk of service impairment, interruption or losses in life cycle costs reaches some predefined level. Implicitly the owners define herewith the accepted risk which can be different from country to country, based on social equity principles. This accepted risk depends upon the established performance goals for each component or combination of bridge components.

The QC plan mirrors these findings and is used for maintenance planning by defining a criteria for triggering maintenance interventions. Clearly, these QC plans have to be established for each individual bridge. They perform the basis for the asset management of this type of roadway infrastructure. The objective of this task is to establish a procedure, based on Bayesian nets or other heuristic rules used worldwide, which would allow the bridge owner to define a QC plan for each individual bridge.

The milestone for this task (M3) is to prepare a report with detailed explanation of the steps towards the establishment of a QC plan for different types of bridges until the middle of year 3 . This outcome will constitute the basis of WG5, being also used by WG4.

\subsection{WG4: Implementation in a Case Study}

During this task a set of roadway bridges, belonging to different COST countries and preferably with identical typologies, will be identified. Then, for those bridges, it will be obtained the performance indicators (identified in WG1). Such values will be then compared with pre-specified goals (identified in WG2) and, finally, a QC plan will be implemented (detailed description at WG3). Different methodologies for obtaining such indicators, as well as different threshold values, will be used as the basis for benchmarking.

At the end of this task, a QC plan will be applied to such bridges, according to the recommendations established by WG3. The main objective of this study is to show the existing dispersion between obtained performance indicator values and its goals. It is important to note that this will reflect the existing dispersion among QC plans. Also, it will be tested and validated the implemented QC plan, according to the recommendations given by WG3. Obtained results will be discussed within a high level of network of experts in this field. There are several ongoing national research projects in COST countries with which a close interaction may be established within the scope of this task. Namely, some of the roadway bridges which will be used as case study may be selected from those projects. Additionally, there will be several people from industry (e.g. owners, operators, etc.) involved in this working package.

The milestone of this task (M4) is to prepare a data basis from benchmarking, until the middle of year 
4. Obtained results will validate the outcomes of WG1, WG2 and WG3, and will be used by WG5.

\subsection{WG5: Drafting of guideline/recommendations}

In this task it will be joined the work developed in other working packages (especially from WG1, WG2 and WG3) with the objective of writing a guideline, and recommendations, for the implementation of a QC plan for roadway bridges that could be adopted by several roadway agencies. The main goal will be the preparation of a document that can be easily adopted by engineers facing the management of new and existing bridges.

Therefore, the format and content should follow the existing codes / guidelines / recommendations used today by agencies. Hence, the first step will be the analysis of existing documentation and work developed in other similar research programs and by standardization committees at national and international level.

Due to the objective proposed, this working package will have a strong interrelation with all the other working packages, becoming an output for WG6 (dissemination). Finally, the milestone of this task (M5) is the development of a new guideline for the establishment of QC plans in roadway bridges until the end of year 4 .

\section{DISSEMINATION PLAN}

The success of this Action can be measured by the impact it has on the civil engineering community composed by, among others, infrastructure owners and operators, standardization bodies, scientific community, practicing engineers and other professionals.

The Action will enable useful synergies and disseminate the results to several target groups and end users, namely: (i) roadway owners and operators; (ii) designers and consultant companies; (iii) equipment and software companies; (iv) researchers and engineers in the field of asset management and structural engineering; (v) relevant national, European and international associations and confederations; (vi) authorities and policy makers at regional and European level; (vii) research community, relevant standardization bodies and code writers; and (viii) teachers and students of engineering schools.

It is important to note that the achievements of this Action will become available in an illustrative, executable and user friendly way, so that it is possible to assure its practical application. Moreover, they will be further disseminated to active research frameworks such as HORIZON 2020 as well as to national research frameworks.
The MC will assure, through WG6, effective dissemination mechanisms to publish the progress and results of the Action. Among these tools are: (i) website, leaflets, posters, TV channels, radio stations, newsletters and online service news; (ii) workshops, conferences, training schools and STSM (Short Term Scientific Missions); (iii) Conferences, peer-reviewed articles and reports issued by the Action; and (iv) Guideline and link to standardization.

A website was developed - http://www.tu1406.eu - containing information about the Action itself which will be continuously updated. Also available are a facebook page and a LinkedIn account, accessible by https://www.facebook.com/tu1406ca and https://www.linkedin.com/company/tu1406, respectively.

Workshops, conferences, training schools and teaching activities will allow to explain the performed scientific work between researchers, industry and stakeholders, as well as the practical approach of the developed guideline. STSMs are specially promoted to early-stage researchers that encourage the synergy among institutions, accelerate the learning of students and provide academia and industry with highly trained staff.

The achievements of this Action will be published in international conferences, as they bring together researchers, academia and industry in an open-discussion forum, in peer-reviewed articles, as they are an important tool to prove the impact and accuracy of obtained results and to make them available for the future, and in technical reports (state-ofart reports and others) which will have the involvement of peer-reviewers from other countries.

The guideline to be achieved will include the establishment of QC plans in roadway bridges, comprising performance indicators assessment and its goals, as well as the obtained results. This recommendation paper will be developed in close cooperation with scientific and practicing community and linked to European and international standards.

\section{CURRENT DEVELOPMENTS}

In order to achieve the proposed objectives, the Action will take place with the completion of several steps which were framed in the existing working groups. At this moment, the most active is WG1, dedicated to performance indicators.

Within this WG, which is currently in operation, the first step was to obtain documents from infrastructure owners related to inspections and quality control plans. These documents are being currently subject to a screening process that will allow to break them down into chapters, to discard non relevant informations and to assign chapters to the working groups. 
The information derived from this process, in order to be more easily used, will be inserted in a structured database, Figure 3, which has been meanwhile developed. This database will be the subject of interaction between the working groups WG1, WG2 and WG3. A person was nominated, per each involved country, to perform each of these tasks.

Due to the considerable number of countries and experts involved in the process, the database will be accompanied by a glossary aimed to establish a common language, allowing to understand the context in which expressions and definitions are used.

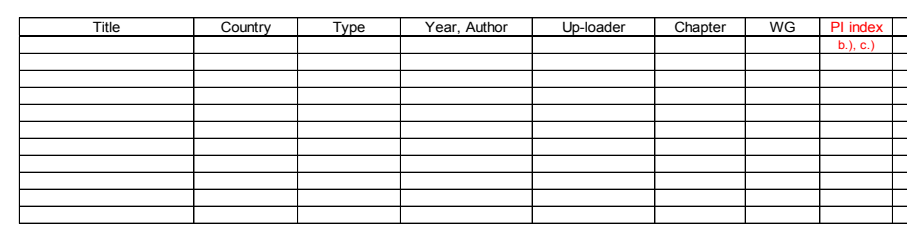

\begin{tabular}{|c|c|c|c|c|c|c|}
\hline PI index & PI level & PI method & Evaluation & Threshold & Goal & Criteria \\
\hline
\end{tabular}

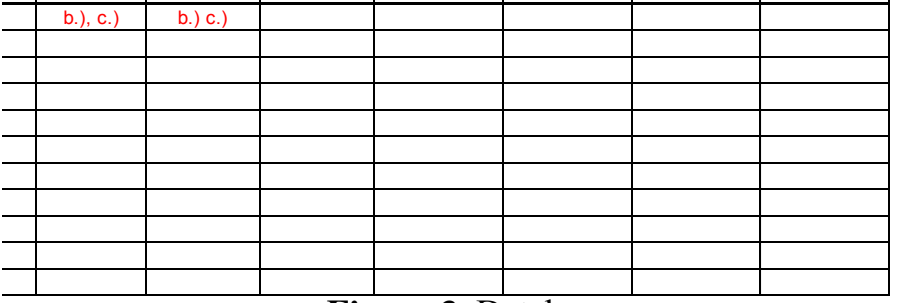

Figure 3. Database.

The information will be structured in three different performance indexing chapters: (i) index; (ii) level; and (iii) method.

The performance index consists in the identification of type of indicator the information regards to. The index can be: (i) visual appearance; (ii) safety (ULS); (iii) serviceability (SLS); (iv) durability (DLS); (v) availability; (vi) cost efficiency; (vii) environmental; (viii) social equity; (ix) structure service life; and (x) maintenance activities.

The performance level regards to the type of infrastructure that is subjected to evaluation: (i) component; (ii) object/system; and (iii) network.

Finally the performance method concerns to the type of evaluation: (i) inspection and survey; (ii) condition monitoring; (iii) condition evaluation; and (iv) condition testing.

The final relevant information to be inserted in the database regards to the condition assessment and decision making. This data consists in the identification of type of evaluated component (evaluation), the threshold limit of the evaluation (threshold), the goal (e.g. reliability level) and finally the criteria (e.g. min- maximizing).

Further along the work to be developed within WG1, the described process will be applied to other documents, namely to evaluation documents and finally to research documents. This methodology will gather information from very different types of sources, from industry to research,
This methodology will allow to gather information from several different types of sources, hoping to allow the establishment of a guideline that is as comprehensive as possible, allowing to identify key factors that are responsible for bridge performance.

\section{ACKNOWLEDGMENTS}

This article is based upon work from COST Action TU-1406, Quality specifications for roadway bridges, standardization at a European level (BridgeSpec), supported by COST (European Cooperation in Science and Technology).

\section{REFERENCES}

Adelaide, L., Richard, B., Ragueneau, F. \& Cremona, C. 2011. A simplified numerical approach of global behaviour of RC beams degraded by corrosion, European Journal of Civil and Environmental Engineering 16 414-439.

Arangio, S. \& Beck, J. L. 2012. Bayesian neural networks for bridges integrity assessment, Structural Control \& Health Monitoring, 19(1) 3-21.

Biondini, F. \& Frangopol, D. M. 2008. Probabilistic Limit Analysis and Lifetime Prediction of Concrete Structures, Structure and Infrastructure Engineering 4(5) 399-412.

Bjegovic, D., Serdar, M., Oslakovic \& I., Gulikers, J. 2013. Local detailed inspection methods to determine concrete properties on structures, Materials and corrosion. 64(2) 135-140.

Coronelli, D., Zandi Hanjari, K. \& Lundgren, K. 2013. Severely Corroded RC with Cover Cracking. Journal of Structural Engineering 139 (2) 221-232.

European Cooperation in the field of Scientific and Technical Research - COST. 2003. Memorandum of Understanding for COST Action 354.

European Cooperation in the field of Scientific and Technical Research - COST. 2005. Memorandum of Understanding for COST Action C25.

European Cooperation in the field of Scientific and Technical Research - COST. 2014. Memorandum of Understanding for COST Action TU1406.

Hanjari, K. Z., Kettil, P. \& Lundgren, K. 2013. Modeling the structural behavior of frost-damaged reinforced concrete structures. Structure and Infrastructure Engineering, 9(5) 416-431.

Ivankovic, A., Franetovic, M. \& Radic, J. 2013. Assessment of Bridges in Aggressive Maritime Environment, IABSE Symposium, Rotterdam: Assessment, Upgrading and Refurbishment of Infrastructures, pp. 614-621(8).

Jensen, J. S., Casas, J. R., Karoumi, R., Plos, M., Cremona, C., Melbourne, C., Wisniewski, D. \& Sloth, M. 2009. Guideline for load and resistance 
assessment of existing European railway bridges. Structure and Infrastructure Engineering.

Kumar, P. \& Imam, B. 2013. Footprints of air pollution and changing environment on the sustainability of built infrastructure, Science of The Total Environment 444(0) 85-101.

Kuosa, H., Ferreira, R. M., Holt, E., Leivo, M. \& Vesikari, E. 2014. Effect of coupled deterioration by freeze-thaw, carbonation and chlorides on concrete service life. Cement and Concrete Composites. 4732 40.

Landolfo, R., Cascini, L. \& Portioli, F. 2011. Sustainability of steel structures: Towards an integrated approach to life-time engineering design, Frontiers of Architecture and Civil Engineering in China 5(3) 304-314.

Linneberg, P., Zinck, M. \& Christensen, K. V. 2012. Reliability Based Inspection and Reliability Centred Maintenance, Proceedings of the 6th International Conference on Bridge Maintenance, Safety and Management (IABMAS), Stresa, Lake Maggiore, Italy.

Linneberg, P., Solgaard, A. O. S., Eriksen, K. \& Jensen, J. S. 2014. Challenges within Life Cycle Cost (LCC) Studies and Life Cycle Assessment (LCA), Proceedings of the 7 th International Conference on Bridge Maintenance, Safety and Management (IABMAS), Shanghai, China.

Mašovic, S. \& Hajdin, R. 2014 Modelling of bridge elements deterioration for Serbian bridge inventory, Journal of Structure and Infrastructure Engineering, 10(8) 976-987.

Matos, J. C., Cruz, P. J. S., Valente, M. I. B. \& Neves, L. C. 2012. An advanced reliability procedure for lifetime assessment of Structures: Application to reinforced concrete beams, fib Symposium, Stockholm - Sweden.

Meda, A., Mostosi, S., Rinaldi \& Z., Riva, P. 2014. Experimental evaluation of the corrosion influence on the cyclic behaviour of R.C. columns, Structural Engineering, In Press.

Novák, D., Pukl, R., Strauss, A. \& Teplý, B. 2012. Reliability assessment of concrete bridges. Proceedings of the 6th International Conference on Bridge Maintenance, Safety and Management (IABMAS), Stresa, Lake Maggiore, Italy.

Novák, D., Pukl, R., Teplý, B. \& Lehký, D., Šomodíková, M., Dolezel, J. 2013. Reliability and durability of concrete structures under complex conditions. Proceedings of the 7 th International Conference on Concrete under Severe Conditions Environment and Loading, Nanjing, China, 10851091.

Orcesi, A. \& Cremona, C. 2010. A Bridge Network Maintenance Framework For Pareto Optimization Of Stakeholders/Users Costs, Reliability Engineering and System Safety 95 1230-1243.

Oslakovic, I., Bjegovic, D. \& Mikulic, D. 2010. Evaluation of service life design models on concrete structures exposed to marine environment. Materials and Structures. 43 1397-1412.

Santos, J. P., Cremona, C., Orcesi, A. \& Silveira, P. 2013. Multivariate statistical analysis for early damage detection, Engineering Structures 56 273285.

Strauss, A., Wendner, R., Bergmeister, K. \& Costa, C. 2013. Numerically and Experimentally Based Reliability Assessment of a Concrete Bridge Subjected to Chloride-Induced Deterioration, Journal of Infrastructure Systems 19 (2) 166-175. 